\title{
KAJIAN POTENSI DAN PRIORITAS LOKASI DRY PORT DI MALANG DAN PASURUAN
}

\section{Study of Potency and Location Priority of Dry Port in Malang and Pasuruan}

\author{
Rahadi Bintang ${ }^{1}$, Harnen Sulistio ${ }^{2}$, M Zainul Arifin ${ }^{3}$ \\ ${ }^{1}$ Jurusan Teknik Sipil, Fakultas Teknik, Universitas Brawijaya \\ Jl. M.T. Haryono No. 167, Malang-65145, Jawa Timur \\ Email : rahabin00@gmail.com \\ 2,3 Jurusan Teknik Sipil, Fakultas Teknik, Universitas Brawijaya \\ J1. M.T. Haryono No. 167, Malang-65145, Jawa Timur
}

\begin{abstract}
The objectives of this study are knowing the current logistic performance based on customers perceptions, knowing the probability of dry port's usage and the recommendations of dry port location with high priority in Malang and Pasuruan. This study uses Principle component analysis, stated preference dan analytic hierarchy process. Based on the results, the logistic performance index of Tanjung Perak Port-Malang route is 3.4, relatively even with Tanjung Perak Port-Pasuruan route that has index 3.41 at likert scale. For the both routes, commodity and transportation infrastructure have low score, less than 3 at likert scale. The probability usage is $88.95 \%$ when dry port gives 3 days shorter in dwelling time, predicted lead time, five hundred thousand rupiahs cheaper in transportation and storage cost and 2 hours faster in travel time for logistic activities of a 20 feet container on Tanjung Perak Port-Pasuruan route. Pasuruan with priority weight $57.66 \%$ is more prioritized than Malang which has priority weight $42.34 \%$ as dry port location. To optimize the implementation of dry port in proposed location, increasing the commodity, transportation infrastructure and cargo clearance services at dry port integrated to seaport are recommended
\end{abstract}

Keywords: Dwelling Time, Dry Port, PCA, AHP, SP

\begin{abstract}
Abstrak
Kajian ini bertujuan untuk mengetahui kinerja sistem logistik saat ini berdasarkan persepsi pengguna jasa, preferensi calon pengguna jasa terhadap potensi dry port dan rekomendasi lokasi yang memiliki prioritas tinggi untuk pembangunan dry port di Malang dan Pasuruan. Metode yang digunakan adalah Principle Component Analysis, Analytic Hierarchy Process dan Stated Preference. Berdasarkan hasil kajian diketahui bahwa indeks kinerja logistik rute Pelabuhan Tanjung Perak-Malang dan Pelabuhan Tanjung Perak-Pasuran relatif sama yaitu untuk Malang 3.40 dan Pasuruan 3.41 pada skala likert. Faktor yang perlu ditingkatkan pada kinerja logistik kedua rute adalah faktor komoditas dan faktor infrastruktur transportasi dimana memiliki skor $<3$ skala likert. Pasuruan memiliki bobot prioritas sebesar 57.66\% lebih tinggi dari Malang sebesar 42.34\% sebagai lokasi pembanguna dry port. Probabilitas penggunaan dry port dengan dwelling time lebih cepat 3 hari, lead time terprediksi, biaya transportasi dan pergudangan lebih murah Rp. 500000,- dan waktu tempuh lebih cepat 2 jam untuk kegiatan logistik kontaner 20 feet pada rute Pelabuhan Tanjung-Pasuruan sebesar $88.95 \%$. Untuk mengoptimalkan pelaksanaan rencana pembangunan dry port pada lokasi yang memiliki prioritas tinggi, direkomendasikan untuk peningkatan komoditas, infrastruktur transportasi dan pelayanan dokumen barang di dry port yang terintegrasi dengan seaport.
\end{abstract}

Kata Kunci: Dwelling Time, Dry Port, PCA, AHP, SP

\section{PENDAHULUAN}

Berdasarkan data Kantor Otoritas Pelabuhan Tanjung Perak Surabaya, pada tahun 2014 arus peti kemas di Pelabuhan Tanjung Perak mencapai 2.383.890 TEUs. Jumlah ini telah melampaui kapasitas petikemas Pelabuhan Tanjung Perak yaitu sekitar 2,1 juta TEUs.

Untuk merespon peningkatan volume kontainer, kongesti dan keterbatasan kapasitas, pelabuhan dapat meningkatkan penerapan konsep inland container depots (ICDs) sebagai strategi peningkatan kapasitas pelabuhan (Jovin J.M. \& Youvang H.,2012:7149). Konsep ICDs ini pada 
prinsipnya sama dengan dry port. Di wilayah hinterland sebelah Selatan Pelabuhan Tanjung Perak, Malang dan Pasuruan menjadi daerah yang berpotensi sebagai lokasi pembangunan dry port. Berdasarkan RTRW dan Tatrawil Propinsi Jawa Timur, Malang direncanakan sebagai lokasi $d r y$ port sedangkan Pasuruan juga telah direncanakan dalam Tatrawil Jawa Timur dan dalam penelitian yang dilakukan BKPM pada tahun 2012 disebutkan Pasuruan lebih ideal untuk pembangunan $d r y$ port. Dengan demikian, diperlukan kajian terkait potensi dan prioritas lokasi dry port pada kedua wilayah tersebut.

\section{Logistik}

Logistik merupakan bagian dari proses rantai suplai yang berfungsi merencanakan,melaksanakan, mengontrol secara efektif, efisien proses pengadaan, pengolaan, penyimpanan barang, pelayanan dan informasi mulai dari titik awal (pont of origin) hingga titik konsumsi (point of consumption) dengan tujuan memenuhi kebutuhankonsumen (Dwitasari dkk, 2010:2$1)$.

Berdasarkan pengukuran indeks kinerja logistik yang dilakukan oleh World Bank tahun 2014, kinerja logistik Indonesia berada di urutan ke 53 dari 160 negara, masih tertinggal dari negara-negara ASEAN seperti Singapura, Malaysia, Thailand dan Vietnam.

Dalam Cetak Biru Pengembangan Sistem Logistik Nasional, Pemerintah telah merumuskan strategi untukmeningkatkan kinerja sistem logistik nasional diantaranya peningkatan infrastruktur transportasi multimoda dimana optimalisasi $d r y$ port menjadi salah satu program yang direncanakan.

\section{Dry Port}

Dry port adalah sebuah terminal intermodal di daerah pedalaman (inland/hinterland) yang terhubung secara langsung ke pelabuhan laut dengan alat angkut berkapasitas besar, lebih diutamakan rel/kereta api, dimana para pengguna jasa dapat memasukkan atau mengeluarkan barang/kontainer seperti di pelabuhan laut (Roso dkk, 2009:81).

Berdasar jarak ke sea port, dry port dikategorikanmenjadi 3 jenis yaitu: (BKPM, 2012:9)

- Distant dry port ( berjarak $>500 \mathrm{~km}$ )

- $\quad$ Midrange dry port(berjarak $100 \mathrm{~km}$ s.d. $500 \mathrm{~km})$

\section{- $\quad$ Close dry port(berjarak <100 km)}

\section{Principle Component Analysis}

Principal Component Analysis (PCA) merupakan sebutan umum bagi sebuah teknik yang menggunakan prinsip dasar matematika untuk menjadikan jumlah variabel-variabel yang kemungkinan saling berkorelasi menjadi lebih sedikit dimana variabel yang terbentuk disebut komponen utama/principal

component (Richardson, 2009:2).

Secara umum, tahapan penggunaan metode Principal Component Analysis dapat diuraikan (Jelantik dkk, 2014:37-38):

- Menentukan variabel penelitian yang akan dianalisa dengan ketentuan nilai $\mathrm{KMO}>0,5$ dengan signifikansi 0,05 dan MSA bernilai $0,5 \leq \mathrm{MSA} \leq 1$.

- Pembentukan faktor dengan ekstraksi variabeldengan ketentuan faktor terbentuk jika eigen value $\geq 1$.

- Penentuan/pengelompokan variabel-variabel ke dalam faktor-faktor yang terbentuk. Suatu variabel masuk dalam suatu faktor apabila nilai korelasi yang terbentuk paling besar diantara nilai korelasi variabel tersebut dengan faktor yang lain. Untuk lebih jelas mengetauhi nilai korelasi antara variabel dan faktor maka dilakukan rotasi matrik komponen.

- Penamaan faktor

\section{Stated Preference}

Kroes \& Sheldon (1988:13) menyatakan Stated preference menjadi metode pilihan yang menarik dalam penelitian di bidang transportasi. Dalam metode ini, pengontrolan penelitian mudah dilakukan karena peneliti yang membuat skenario atau kondisi yang akan dinilai oleh responden, lebih fleksibel terhadap variabel yang bervariasi dan lebih murah dalam pengaplikasiannya.

Dalam membuat desain eksperimen, jumlah kombinasi skenario pilihan yang ditawarkan kepada responden dapat dihitung dengan memangkatkan jumlah level atribut $\mathrm{n}$ dengan jumlah atributnya a atau dapat ditulis $n^{\mathrm{a}}$. Desain eksperimen yang menggunakan seluruh kombinasi pilihan disebut desain full factorial. Desain eksperimen ini dapat menghasilkan jumlah kombinasi pilihan yang banyak sehingga menyulitkan responden. Jumlah kombinasi pilihan yang disarankan adalah berkisar 9-16 
(Kroes \& Sheldon, 1988:14). Untuk mengatasi permasalahan besarnya jumlah kombinasi pilihan dalam desain eksprimen digunakan desain fractional factorial yaitu desain eksperimen yang tidak menggunakan seluruh kombinasi pilihan.

Beberapa metode dapat digunakan untuk menganalisa lebih lanjut data hasil stated preference. Metode analisa dipilih berdasarkan jenis data respon responden. Untuk data berbentuk choice dapat dianalisa dengan metode logit, data berbentuk ranking dapat dianalisa dengan metode Monotomic Analysis of Variance (MONANOVA) dan juga metode logit, sedangkan data dalam bentuk rating dapat dianalisa dengan metode regresi. Fungsi logit binomial yang dapat ditulis:

$$
P_{1}=\frac{\exp ^{\left(\mathrm{U}_{1}\right)}}{\exp ^{\left(\mathrm{U}_{1}\right)}+\exp ^{\left(\mathrm{U}_{2}\right)}}
$$

Dimana :

$\begin{array}{ll}\mathrm{P}_{1} & \text { : probabilitas pilihan } 1 \\ \mathrm{U}_{1} & : \text { Utilitas pilihan } 1 \\ \mathrm{U}_{2} & : \text { Utilitas pilihan } 2\end{array}$

Fungsi utilitas diasumsikan sebagai fungsi linear dan ditulis dalam bentuk berikut:

$\mathrm{U}_{\mathrm{j}}=\mathrm{b}_{0}+\mathrm{b}_{1} \mathrm{x}_{1}+\mathrm{b}_{2} \mathrm{x}_{2 .}+\ldots \ldots+\mathrm{b}_{\mathrm{n}} \mathrm{x}_{\mathrm{n}}$

Dimana :

$\mathrm{U}_{\mathrm{j}} \quad$ : utilitas pilihan $\mathrm{j}$

$\mathrm{b}_{0} \quad$ : konstanta

$b_{1} \ldots b_{n}$ : koefisien atribut

$\mathrm{x}_{1} \ldots . \mathrm{x}_{\mathrm{n}}$ : atribut model

Selisih utilitas dua pilihan dapat dirumuskan:

$$
\begin{gathered}
\mathrm{U}_{1}-\mathrm{U}_{2}=\mathrm{b}_{0}+\mathrm{b}_{1}\left(\mathrm{x}_{11}-\mathrm{x}_{12}\right)+\mathrm{b}_{2}\left(\mathrm{x}_{21}-\mathrm{x}_{22}\right) .+\ldots . .+ \\
\mathrm{b}_{\mathrm{n}}\left(\mathrm{x}_{\mathrm{n} 1}-\mathrm{x}_{\mathrm{n} 2}\right)
\end{gathered}
$$

Dengan menggunakan transformasiBerkson Theil, fungsi selisih utilitas antara dua pilihan dapat ditulis:

$\mathrm{U}_{1}-\mathrm{U}_{2}=\ln \left(\mathrm{P}_{1} / 1-\mathrm{P}_{1}\right)$

Berdasarkan transformasi tersebut, pilihan reponden dari skala rating ditransformasikan ke dalam skala proabilitas yaitu angka 1 $=0,9 ;$ angka $2=0,7 ;$ angka $3=0,5 ;$ angka $4=$ 0,3 dan angka $5=0,1$. Skala probabilitas tersebut kemudian ditransfiormasikan menjadi skala utilitas dan didapatkan nilai secara berturut-turut 2,1972;0,8473;0,000; - 0,8473; 2,1972 .

Besarnya pengaruh persentase perubahan dari selisih utilitas terhadap persentase perubahan probabilitas pilihan yang ditawarkan dapat diketahui dari nilai elastisitas. Elastisitas ada dua jenis yaitu elastisitas langsung (direct-elasticity) dan elastisitas silang (crosselasticity). Elastisitas langsung dalam probabilitas pemilihan 2 alternatif dapat diartikan sebagai perubahan probabilitas suatu alternatif akibat perubahan persentase pada salah satu atribut alternatif tersebut. Sedangkan elastisitas silang dalam probabilitas pemilihan 2 alternatif dapat diartikan sebagai perubahan probabilitas suatu alternatif akibat perubahan persentase pada salah satu atribut pada alternatif lainnya.

\section{Analytic Hierarchy Process}

Analytic Hierarchy Process (AHP) merupakan salah satu bentuk dari Decision Support System (DSS) atau Sistem Pendukung Keputusan. Sistem DSS bertujuan untuk meningkatkan proses dan kualitas hasil pengambilan keputusan dimana DSS dapat memadukan data dan pengetahuan untuk meningkatkan efektifitas dan efisiensi dalam proses pengambilan keputusan (Maharani dkk., 2010:104).

Tahapan metode Analytic Hierarchy Process secara garis besardapat diuraikan sebagai berikut: (Saaty, 2008:85)

- Mendefinisikan permasalahan

- Membuat struktur hierarki keputusan mulai dari paling atas adalah tujuan keputusan, dibagian tengah adalah kriteria dan level yang paling bawah adalah kumpulan dari alternatif.

- Membuat matrik perbandingan berpasangan (pairwise comparison matrices). Setiap elemen yang berada di level lebih atas digunakan untuk membandingkan elemen yang berada tepat di bawahnya

- Menggunakan prioritas yang didapatkan dari perbandingan untuk pembobotan prioritas pada level yang berada tepat di bawahnya.

Untuk membandingkan penilaian elemenelemen pada setiap level, responden diminta untuk memberikan skor/nilai pada elemen secara berpasangan dalam rentang skala rating 1 sampai dengan 9 seperti yang digunakan oleh Thomas L. Saaty.

\section{METODE PENELITIAN}

Tahapan kajian yang dilakukan dapat dilihat pada diagram alir berikut. 


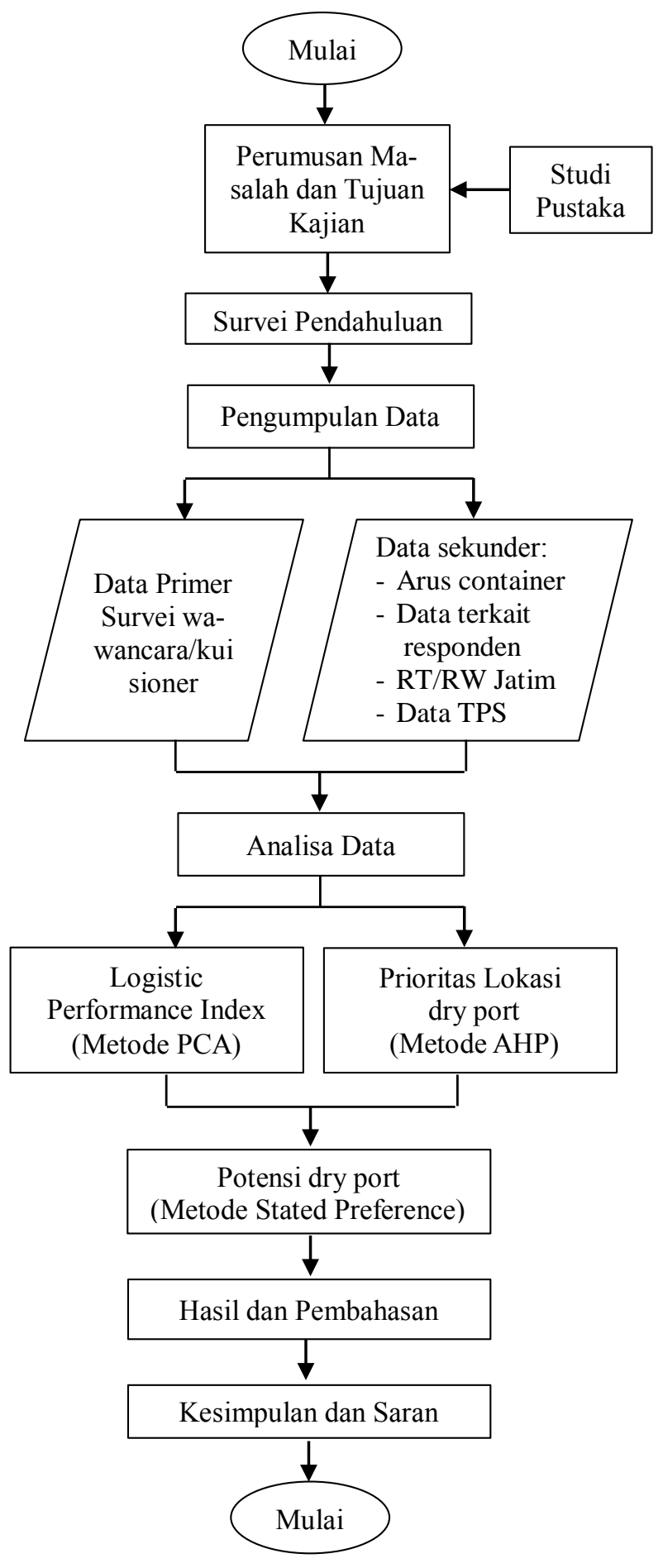

Gambar 1 . Diagram Alir Kajian

Metode pengumpulan data yang digunakan dalam kajian adalah metode wawancara, penyebaran kuisioner, studi pustaka dan permintaan data langsung kepada pihakpihak terkait.

Terdapat 3 kuisioner yang digunakan dalam kajian ini yaitu:
- Kuisioner pengukuran kinerja logistik rute Pelabuhan Tanjung Perak-Malang dan Pelabuhan Tanjung Perak-Pasuruan. Kuisioner ini menggunakan penilaian skala likert dengan skala 1:sangat rendah, 2: rendah, 3: sedang, 4: tinggi dan 5:sangat tinggi. Variabel yang digunakan adalah sebagai berikut.

- komoditas

$\mathrm{V}_{1.1}$ : frekuensi pengiriman komoditas

$\mathrm{V}_{1.2}:$ jumlah/volume pengiriman komoditas

- pelayanan dan penyedia jasa logistik

$\mathrm{V}_{2.1}$ : kapasitas/daya tampung

$\mathrm{V}_{2.2}$ : kompetensi/kemampuan

- infrastruktur transportasi

$\mathrm{V}_{3.1}$ : kondisi infrastruktur transportasi berbasis jalan

$\mathrm{V}_{3.2}$ : kondisi infrastruktur transportasi berbasis rel/kereta api

$\mathrm{V}_{3.3}$ : ketepatan waktu pengiriman pada rute pelabuhan - hinterland

$\mathrm{V}_{3.4}$ : konektivitas transportasi antar moda

$\mathrm{V}_{3.5}$ : kemudahan menetapkan biaya logistik yang kompetitif

- infrastruktur komunikasi, informasi dan teknologi

$\mathrm{V}_{4.1}: \quad$ kemudahan terkait kepabeanan

$\mathrm{V}_{4.2}$ : kecepatan clearance komoditas

$\mathrm{V}_{4.3}: \quad$ transparansi proses kepabeanan

$\mathrm{V}_{4.4}$ : penggunanaan teknologi komunikasi dan informasi dalam proses kepabeanan

$\mathrm{V}_{4.5}$ : kemudahan dalam melacak dan mengetahui status pengiriman

$\mathrm{V}_{4.6}$ : ketepatan waktu dalam proses ekspor-impor

- SDM petugas instansi pemerintah dan stakeholder lainnya

$\mathrm{V}_{5.1}$ : kuantitas SDM

$\mathrm{V}_{5.2}$ : kualitas SDM

- regulasi, kabijakan dan standar dalam sistem logistik

$\mathrm{V}_{6.1}$ : ketersediaan 


$$
\mathrm{V}_{6.2} \text { : penerapan }
$$

- Kuisioner prioritas lokasi dry port yang ditawarkan. Penilaian kuisioner menggunakan skala rating 1 sampai dengan 9 yang digunakan oleh Thomas L. Saaty. Struktur hierarki yang digunakan dapat dilihat pada gambar 2 .

Level 1 : Goal

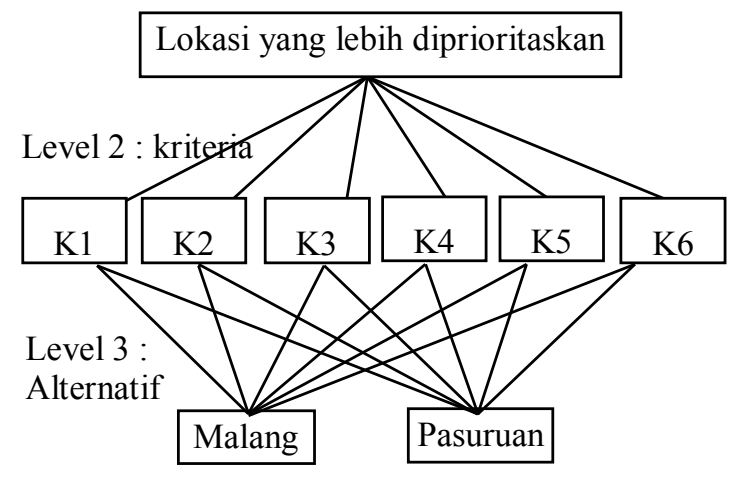

Gambar 2 . Struktur Hierarki Keputusan

Keterangan:

K1 : Kondisi topografi lokasi

K2 : Aksesibilitas wilayah

K3 : Kesesuaian dengan RTRW\&Tatrawil Jawa Timur

K4 : Potensi Hinterland

K5 : Infrastruktur Transportasi

K6 : Dukungan Kebijakan Pemda II

- Kuisioner preferensi calon pengguna jasa terhadap potensi dry port. Penilaian menggunakan skala rating yaitu: 1: pasti memilih dry port, 2: mungkin memilih dry port, 3: pilihan berimbang, 4: mungkin memilih sislog existing dan 5: pasti memilih sislog existing. Atribut yang ditawarkan berjumlah 7 dan masing-masing memiliki 2 level. Desain instrumen menggunakan fractional factorial dengan 16 skenario (Plan 7 AMCP 706112,1972:12-18). Atribut dan level dapat dilihat pada tabel 1 .

Metode analisa yang digunakan dalam kajian ada 3 yaitu:

- Principle Component Analysis (PCA) untuk menganalisis kinerja sistem logitik pada rute yang dikaji.

- Stated Preference (SP) menggunakan metode analisis data model logit binomial untuk menganalisis pemilihan penggunaan dry port.
- Analytic Hierarchy Process (AHP) untuk menganalisis prioritas lokasi dry port yang diusulkan.

Tabel 1. Atribut dan level atribut pemilihan sistem logistik

\begin{tabular}{|c|c|c|c|}
\hline \multirow[b]{2}{*}{ No } & \multirow[b]{2}{*}{ Atribut } & \multicolumn{2}{|c|}{ Level atribut } \\
\hline & & $\begin{array}{l}\text { Level } \\
\text { rendah }\end{array}$ & $\begin{array}{l}\text { Level } \\
\text { tinggi }\end{array}$ \\
\hline 1 & Dwelling time & 5 hari & 2 hari \\
\hline 2 & Segel Elektronik & Tidak ada & Ada \\
\hline 3 & Lead time & $\begin{array}{l}\text { Sulit terpred- } \\
\text { iksi }\end{array}$ & $\begin{array}{l}\text { Terpred- } \\
\text { iksi }\end{array}$ \\
\hline 4 & $\begin{array}{l}\text { Biaya transport } \\
\text { dan pergudangan }\end{array}$ & 2.5 juta & 2 juta \\
\hline 5 & $\begin{array}{l}\text { Bebas biaya } \\
\text { penumpukan }\end{array}$ & Tidak ada & $\begin{array}{l}5 \text { hari } \\
\text { pertama }\end{array}$ \\
\hline 6 & Waktu Tempuh & 4 jam & 2 jam \\
\hline 7 & $\begin{array}{l}\text { Jalur Khusus Ma- } \\
\text { suk ke Pelabuhan }\end{array}$ & Tidak ada & Ada \\
\hline
\end{tabular}

Penentuan sampel responden PCA dan SP menggunakan teknik Slovin:

$$
n=\frac{\mathrm{N}}{1+\mathrm{N}(\mathrm{e})^{2}}
$$

dimana:

1 : konstanta

$\mathrm{n}$ : jumlah sampel

$\mathrm{N}$ :jumlah populasi (201 perusahaan

EMKL/JPT)

e : tingkat kesalahan (digunakan 5\%)

Dengan demikian sampel minimal adalah 134 perusahaan. Dalam kajian ini diambil satu perusahaan rata-rata 3 responden. Responden AHP ditentukan sebanyak 25 orang yang berasal dari dari 5 instansi terkait.

\section{HASIL DAN PEMBAHASAN}

Berdasarkan survei yang dilakukan, didapatkan responden untuk kuisioner penilaian kinerja logistik sebanyak 403 responden, kuisioner potensi penggunaan $d r y$ port sebanyak 405 responden dan kuisioner prioritas lokasi dry port sebanyak 25 responden. Data tersebut kemudian dianalisa secara deskriptif.

\section{Kinerja Sistem Logistik}

Kinerja sistem logistik dinilai berdasarkan indeks kinerja logistik. Untuk mendapatkan 
model indeks kinerja logistik yang sama kedua rute, skor penilaian kedua rute pada setiap indikator dirata-rata sebagai data inputan metode PCA. Proses analisis PCA menggunakan bantuan program statistik. Indeks kinerja logistik masingmasing rute didapatkan dengan memasukkan skor penilaian setiap responden ke dalam model component score kinerja logistik dan kemudian diratarata. Berdasarkan hasil analisis metode PCA, dari 19 variabel awal terbentuk 6 variabel baru/komponen utama, dengan nilai KMO 0,739 $(>0,50)$ dengan siknifikansi $0,00(<0,05)$ dan nilai eigen value $71,45 \%$ yang berarti komponen yang terbentuk mampu menerangkan variabel awal sebesar 71,45\%. Keenam komponen utama tersebut yaitu:

- Kompononen 1 (C1) dengan variabel pembentuk: $\mathrm{V}_{4.1}, \mathrm{~V}_{4.2}, \mathrm{~V}_{4.3}, \mathrm{~V}_{4.4}, \mathrm{~V}_{4.5}, \mathrm{~V}_{4.6}$

- Komponen 2 (C2) dengan variabel pembentuk: $\mathrm{V}_{3.1}, \mathrm{~V}_{3.2}, \mathrm{~V}_{3.3}, \mathrm{~V}_{3.4}, \mathrm{~V}_{3.5}$

- Komponen 3 (C3) dengan variabel pembentuk: $\mathrm{V}_{6.1}, \mathrm{~V}_{6.2}$

- Komponen 4 (C4) dengan variabel pembentuk: $\mathrm{V}_{1.1}, \mathrm{~V}_{1.2}$

- Komponen 5 (C5) dengan variabel pembentuk: $\mathrm{V}_{2.1}, \mathrm{~V}_{2.2}$

- Komponen 6 (C6) dengan variabel pembentuk: $\mathrm{V}_{5.1}, \mathrm{~V}_{5.2}$ yaitu:

Model component score yang dihasilkan

$$
\begin{aligned}
* \mathrm{CS}_{1}= & 0,213 \mathrm{~V}_{4.1}+0,220 \mathrm{~V}_{4.2}+0,227 \mathrm{~V}_{4.3} \\
& +0,215 \mathrm{~V}_{4.4}+0,215 \mathrm{~V}_{4.5}+0,190 \\
& \mathrm{~V}_{4.5} \\
{ }^{*} \mathrm{CS}_{2}= & 0,239 \mathrm{~V}_{3.1}+0,237 \mathrm{~V}_{3.2}+0,247 \mathrm{~V}_{3.3} \\
& +0,238 \mathrm{~V}_{3.4}+0,244 \mathrm{~V}_{3.5} \\
& \mathrm{CS} 3=0,526 \mathrm{~V} 6.1+0,526 \mathrm{~V} 6.2 \\
* \mathrm{CS} 4= & 0,552 \mathrm{~V} 1.1+0,552 \mathrm{~V} 1.2 \\
* \mathrm{CS} 5= & 0,555 \mathrm{~V} 2.1+0,555 \mathrm{~V} 2.2 \\
& * \mathrm{CS} 6=0,617 \mathrm{~V} 5.1+0,617 \mathrm{~V} 5.2
\end{aligned}
$$

Berdasarkan hasil analisa, indeks kinerja logistik kedua rute hampir sama nilainya dan berada pada rentang sedang/cukup pada skala likert yaitu untuk rute Pelabuhan Tanjung PerakMalang adalah 3,404 sedangkan rute Pelabuhan Tanjung Perak-Pasuruan adalah 3,414. Variabel yang berada di bawah sedang/cukup adalah komoditas (rute Pelabuhan Tanjung Perak-Malang adalah 2,639 sedangkan rute Pelabuhan Tanjung Perak-Pasuruan adalah 2,693) dan infrastruktur transportasi (rute Pelabuhan Tanjung Perak-Malang adalah 2,923 sedangkan rute Pelabuhan Tanjung Perak-Pasuruan adalah 2,921).

\section{Potensi Pemilihan Dry Port}

Model utilitas selisih dengan bantuan program statistik yaitu:

$$
\begin{aligned}
\mathrm{U}_{\mathrm{D}}-\mathrm{U}_{\mathrm{E}}= & -0,674-0,307 \Delta \mathrm{X}_{1}-1,854 \mathrm{E}-06 \\
& \Delta \mathrm{X}_{4}-0,458 \Delta \mathrm{X}_{6}
\end{aligned}
$$

Dimana :

$\mathrm{U}_{\mathrm{D}}-\mathrm{U}_{\mathrm{E}}$ : utilitas selisih sistem logistik menggunakan dry port dengan sistem logistik existing

$\Delta \mathrm{X}_{1} \quad$ : nilai selisih atribut $d w e l l i n g$ time

$\Delta \mathrm{X}_{4} \quad$ : nilai selisih atribut biaya transportasi dan pergudangan

$\Delta \mathrm{X}_{6} \quad$ : nilai selisih atribut waktu tempuh perjalanan

Dari persamaan tersebut dapat diketahui dari 7 selisih atribut yang digunakan dalam pemodelan, 3 selisih atribut yang berpengaruh terhadap model utilitas selisih.

Nilai konstanta bertanda negatif $(-0,674)$ menunjukkan pada nilai atribut sistem logistik menggunakan dry port sama dengan nilai atribut sistem logistik yang ada saat ini (tanpa dry port), maka nilai utilitas selisih akan bernilai negatif sehingga utilitas penggunaan dry port lebih kecil daripada utilitas sistem logistik existing. Nilai koefisien selisih atribut biaya transportasi dan pergudangan, dwelling time dan waktu tempuh perjalanan bernilai negatif menunjukkan bahwa semakin besar selisih atribut tersebut, maka semakin kecil utilitas selisih penggunaan dry port dalam sistem logistik oleh calon pengguna jasa. Nilai koefisien selisih atribut biaya transportasi dan pergudangan sangat kecil karena nilai selisih atribut dalam pemodelan bernilai sangat besar bila dibandingkan dengan nilai selisih atribut lainnya.

Nilai utilitas selisih seluruh skenario dari model di atas sebagai input model logit biner didapatkan probabilitas penggunaan dry port dan sistem logistik existing seperti pada tabel 2. Dari tabel tersebut, nilai probabilitas penggunaan $d r y$ port terkecil dalam sistem logistik pada rute yang 
ditawarkan adalah 0.3374 atau $33.74 \%$ (lebih kecil daripada nilai probabilitas sistem logistik existing sebesar 0.6626 atau $66.26 \%$ ) yaitu pada skenario 1 dan skenario 7 dimana nilai utilitas selisih bernilai negatif(-0.6740). Pada kedua skenario ini, nilai selisih ketiga atribut dalam model sama dengan nol atau nilai atribut sama dengan nilai atribut sistem logistik existing.

Tabel 2 . Probabilitas pemilihan penggunaan sistem logistik

\begin{tabular}{cccccc}
\hline No & Skenario & $\mathrm{U}_{(\mathrm{d}-\mathrm{e})}$ & $\mathrm{e}^{\mathrm{U}(\mathrm{d}-\mathrm{e})}$ & $\mathrm{Pd}$ & $\mathrm{Pe}$ \\
\hline 1 & $\mathrm{~S} 1 \& \mathrm{~S} 7$ & -0.6750 & 0.5092 & 0.3374 & 0.6626 \\
2 & $\mathrm{~S} 3 \& \mathrm{~S} 5$ & 0.2410 & 1.2725 & 0.5600 & 0.4400 \\
3 & $\mathrm{~S} 2 \& \mathrm{~S} 8$ & 0.2460 & 1.2789 & 0.5612 & 0.4388 \\
4 & $\mathrm{~S} 11 \& \mathrm{~S} 13$ & 0.2490 & 1.2827 & 0.5619 & 0.4381 \\
5 & $\mathrm{~S} 4 \& \mathrm{S6}$ & 1.1620 & 3.1963 & 0.7617 & 0.2383 \\
6 & $\mathrm{~S} 9 \& \mathrm{~S} 15$ & 1.1650 & 3.2059 & 0.7622 & 0.2378 \\
7 & $\mathrm{~S} 12 \& \mathrm{~S} 14$ & 1.1700 & 3.2220 & 0.7631 & 0.2369 \\
8 & $\mathrm{~S} 10 \& \mathrm{~S} 16$ & 2.0860 & 8.0526 & 0.8895 & 0.1105 \\
\hline
\end{tabular}

Sumber: Hasil Analisa Data Primer 2015

Nilai utilitas selisih bernilai positif terdapat pada skenario selain kedua skenario di atas. Utilitas selisih positif dengan nilai terkecil terdapat pada skenario 3 dan 5 yaitu 0,2410 dengan probabilitas pemilihan penggunaan $d r y$ port sebesar 0,5600 atau $56,00 \%$ dimana pada skenario ini selisih atribut dwelling time dan atribut biaya transportasi dan pergudangan sama dengan 0 sedangkan selisih atribut waktu tempuh perjalanan lebih cepat 2 jam. Nilai utilitas selisih positif terbesar terdapat pada skenario 10 dan 16 yaitu 2,086 dengan probabilitas pemilihan penggunaan dry port sebesar 0,8895 atau $88,95 \%$ dimana pada skenario ini $d$ welling time lebih cepat 3 hari, atribut biaya transportasi dan pergudangan lebih murah Rp. 500.000.- dan waktu tempuh perjalanan lebih cepat 2 jam.

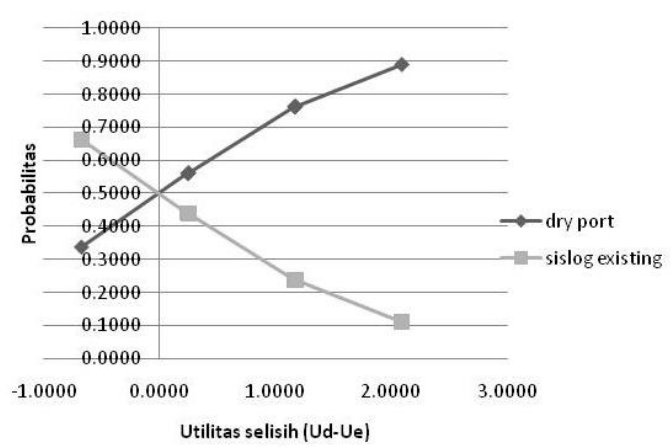

Gambar 3 . Grafik probabilitas pemilihan

$$
\text { sistem logistik }
$$

Dari gambar 3 diketahui bahwa pada nilai utilitas selisih 0 , grafik probabilitas kedua sistem logistik berpotongan pada nilai probabilitas 0,5 atau 50\% sehingga pada titik ini pemilihan sistem logistik menggunakan dry port dengan sistem logistik existing adalah berimbang. Kondisi ini terjadi diantara skenario 1 dan skenario 7 (selisih atribut dalam model $=0$ ) dengan skenario 3 dan skenario 5 (satu atribut memilki level tinggi).

Elastisitas model pemilihan penggunaan dry port dihitung menggunakan elastisitas langsung dengan hasil seperti pada tabel 4.Berdasarkan tabel tersebut, probabilitas penggunaan dry port paling sensitif terhadap perubahan atribut biaya transportasi dan pergudangan.Nilai elastisitas atribut $d$ weiling time, biaya transportasi dan pergudangan serta waktu tempuh perjalan bernilai negatif (-) yang berarti apabila terjadi peningkatan nilai atribut tersebut,maka probabilitas penggunaan dry portakan menurun. Nilai elastisitas dapat dilihat pada tabel 3 .

Tabel 3 . Elastisitas model pemilihan sislog

\begin{tabular}{|c|c|c|c|}
\hline & \multicolumn{3}{|c|}{ Atribut } \\
\hline & $\begin{array}{c}\Delta \text { dwell } \\
\text { time }\end{array}$ & $\Delta$ biaya TP & $\begin{array}{l}\Delta \text { waktu } \\
\text { tempuh }\end{array}$ \\
\hline$\Delta \mathrm{x}$ & -3 & -500000 & -2 \\
\hline Ud1 & -0.6750 & -5.2360 & -2.6670 \\
\hline $\mathrm{Ud} 2$ & 0.2460 & -4.3830 & -1.8190 \\
\hline Pd1 & 0.2848 & 0.2988 & 0.2999 \\
\hline $\operatorname{Pd} 2$ & 0.7152 & 0.7012 & 0.7001 \\
\hline$\Delta \mathrm{Pd}$ & 0.4305 & 0.4024 & 0.4003 \\
\hline $\begin{array}{l}\text { Elastisitas } \\
\text { Langsung }\end{array}$ & -2.5197 & -6.7334 & -2.6699 \\
\hline
\end{tabular}

Sumber: Hasil Analisa Data Primer 2015

\section{Prioritas Lokasi Dry Port}

Berdasarkan analisis prioritas lokasi $d r y$ port, pertimbangan penentuan lokasi dry port adalah infrastruktur transportasi $(24,30 \%)$, potensi hinterland $(20,50 \%)$, aksesibilitas wilayah lokasi $(18,30 \%)$, kesesuaian lokasi dengan RTRW dan Tatrawil (15,00\%), dukungan kebijakan Pemerintah Kabupaten/Kota tempat lokasi dry port $(13,90 \%)$ dan kondisi topografi $(7,80 \%)$. Dengan pertimbangan tersebut, lokasi pembangunan dry port di wilayah Pasuruan memiliki prioritas sebesar 57,66\% atau lebih tinggi dari lokasi di 
wilayah Malang yang memiliki nilai prioritas sebesar $42,34 \%$.

\section{KESIMPULAN DAN SARAN}

\section{Kesimpulan}

- Penilaian kinerja menggunakan 6 faktor yang terbentuk hasil analisis PCA yaitu faktor infrastruktur komunikasi, informasi dan teknologi, faktor infrastruktur transportasi, faktor regulasi, kebijakan dan standar sistem logistik, faktor komoditas, faktor pelayanan dan penyedia jasa logistik dan faktor sumber daya manusia petugas instansi pemerintah dan operator pelabuhan. Dari keenam faktor tersebut, faktor komoditas dan infrastruktur transportasi pada kedua rute memiliki nilai kurang dari cukup/sedang (skor $<3$ skala likert).

- Terdapat 3 atribut yang dipertimbangkan calon pengguna jasa untuk beralih menggunakan dry port yaitu $d$ welling time, biaya transportasi dan pergudangan serta waktu tempuh perjalanan. Calon pengguna jasa masih memilih sistem logistik existing apabila nilai atribut yang ditawarkan sama dengan atribut sistem logistik yang ada saat ini. Pada kelompok skenario ini, probabilitas pemilihan penggunaan $d r y$ port adalah 33,74\%. Probabilitas pemilihan penggunaan $d r y$ port lebih besar dari sistem existing berkisar $56,00 \%$ sampai dengan $88,95 \%$. Berdasarkan elastisitasnya, penambahan nilai atribut akan menurunkan probabilitas penggunaan $d r y$ port.

- Wilayah Kabupaten Pasuruan memiliki bobot prioritas sebesar $57,66 \%$, lebih tinggi dari Wilayah Kabupaten Malang sebesar 42,34\% sebagai lokasi pembangunan $d r y$ port. Untuk mengoptimalkan pelaksanaan pembangunan dry port di lokasi tersebut maka diusulkan halhal sebagai berikut:

- meningkatkan jumlah komoditas unggulan dengan pengembangan sektor ekonomi khususnya bidang industri yang terpusat dan berlokasi berdekatan dengan lokasi rencana dry port sehingga memiliki konektifitas dan aksesibilitas yang tinggi dari keduanya serta mampu meningkatkan efisiensi waktu dan biaya logistik

- meningkatkan infrastruktur transportasi baik jalan seperti pelaksanaan pembangunan jalan tol maupun transportasi berbasis rel seperti pelaksanaan pembangunan double track yang memiliki akses langsung ke wilayah pelabuhan (lebih direkomendasian), sampai ke sisi dermaga sehingga mampu mengurangi waktu tempuh dan dwelling time

- memberikan pelayanan clearance atau pengurusan dokumen barang seperti kepabeanan dan karantina di dry port yang terintegrasi dengan seaport sehingga tidak terjadi tumpang-tindih pengurusan clearance/dokumen barang antara dry port dan seaport, barang langsung dapat dimuat ke/dibongkar dari kapal sehingga mengurangi potensi double-handling cargo.

\section{Saran}

- Untuk kajian/penelitian lebih lanjut dapat dilakukan kajian mengenai kelayakan ekonomi maupun kelayakan finansial pembangunan dry port di Malang dan Pasuruan serta kajian mengenai lokasi secara tepat pada wilayah Malang dan Pasuruan yang ideal untuk pengembangan dry port. Kajian yang menggunakan instrumen penelitian kuisioner, untuk mendapatkan hasil kajian yang lebih akurat, pengambilan data disarankan menggunakan teknik wawancara secara langsung kepada responden sehingga informasi dalam kuisioner dapat secara tepat dan seragam diterima oleh responden.

- Untuk pemerintah dan pihak terkait, dalam penentuan prioritas pembangunan dry port dilokasi yang telah direncakanan agar mempertimbangkan penilaian kriteriakriteria dengan urutan: infrastruktur transportasi, potensi hinterland, aksesibilitas wilayah, kesesuaian dengan RTRW Propinsi dan Tatrawil, dukungan pemerintah daerah tingkat II lokasi dry port dan kondisi topografi lokasi. Dalam pengoperasiannya, untuk keamanan dan jaminan kualitas pengiriman, kegiatan transportasi agar diselenggarakan oleh pihak pengelola dry port 


\section{DAFTAR PUSTAKA}

Anonim. 2012. Peraturan Presiden Nomor 26 Tahun 2012 Tentang Cetak Biru Pengembangan Sistem Logistik Nasional Anonim. 2012. Peraturan Daerah Provinsi Jawa Timur Nomor 5 Tahun 2012 Tentang Rencana Tata Ruang Wilayah Provinsi Tahun 2011 - 2031

Anonim. 2013. Peraturan Gubernur Jawa Timur Nomor 4 Tahun 2013 Tentang Tataran Transportasi Wilayah Propinsi Jawa Timur Tahun 2012 - 2032

Anonim. 1969. Planning And Analysis Of Experiments. http://everyspec.com

Arvis, J.F dkk. 2014. Connecting To Compete Trade Logistic In The Global Economy The Logistics Performance Index And Its Indicators.World Bank Reports. Washington DC: World Bank.

Badan Koordinasi Penanaman Modal. 2012. Identifikasi Peluang Investasi Pelabuhan Kontainer (Dry Port). Laporan Akhir.

Dwitasari, Reslyana dkk. 2010. Penentuan Biaya Logistik Peti Kemas Dari Kawasan Industri Ke Singapura Melalui Pelabuhan Strategis. Laporan Akhir. Jakarta: Kementerian Riset dan Teknologi \& Kemenerian Perhubungan.

Jelantik, I M., Salain, I M. A. K. dan Nadiasa, Mayun. 2014. Analisis Faktor Yang Mempengaruhi Tenaga Kerja Konstruksi Untuk Memiliki Ska/Sktk Pada Kontraktor Di Kabupaten Badung. Jurnal Spektran. Badung: Teknik Sipil Universitas Udayana.

Kroes, E.P. \& Sheldon, R.J.1988. Stated Preference Method: An Introduction. Jurnal of Transport Economics And Policy.. Netherlands: Hague Consulting Group.

Maharrani, R. H., Syukur, A. \& Tyas Catur .2010. Penerapan Metode Analytical Hierarchi Process Dalam Penerimaan Karyawan Pada PT. Pasir Besi Indonesia. Jurnal Teknologi Informasi. Hal: 102-114.
Semarang: Teknik Informatika Universitas Dian Nuswantoro.

Richardson, Mark. 2009. Principal Component Analysis. http://www.dsc.ufcg.edu. Roso, V.,Woxenius, J., \& Lumsden, Kenth. 2008. The Dry Port Concept: Connecting Container Seaports With The Hinterland. Journal of Transport Geography(2008). Hal: 1-8.Göteborg: Division of Logistics and Transportation, Chalmers University of Technology.

Saaty, Thomas L. 2008. Decision Making With The Analytic Hierarchy Process. Int. J. Services Sciences. Pittsburgh: Katz Graduate School of Business, University of Pittsburgh,

Wemezi, H Jovin J. \& Huang, Youfang. 2012. Inland Container Depot Integration Into Logistics Networks Based On Network Flow Model: The Tanzanian Perspective. AfricanJournal of Business Management.. Shanghai: Logistics Research Center, Shanghai Maritime University. 